\title{
Left atrial spontaneous echo contrast in patients with permanent pacemakers
}

Tsung-Ming Lee, Sheng-Fang Su, Kuo-Liong Chien, Yueh-Juh Lin, Wen-Jone Chen, Ming-Fong Chen, Chiau-Suong Liau, Yuan-Teh Lee

\begin{abstract}
Objective-To determine the relations between left atrial appendage function, spontaneous echo contrast, and thromboembolism in patients with different modes of permanent pacemakers.

Patients and methods-88 patients with pacemaker implatation and 25 healthy controls in sinus rhythm had transoesophageal echocardiographic examination of the left atrial appendage. Left atrial size, appendage area, peak filling and emptying velocities of the atrial appendage, and the presence or absence of spontaneous echo contrast and thromboembolism were determined. The results in 63 patients with ventricular pacing (group 1, subdivided into subgroup 1A: 42 patients with sinus rhythm, and subgroup 1B: 21 patients with atrial fibrillation) were compared with those in 25 patients with synchronous pacing (group 2), and 25 normal control subjects (group 3).
\end{abstract}

Results-Patients with ventricular pacing had two distinct appendage flow patterns: well defined biphasic filling and emptying waves in subgroup $1 \mathrm{~A}$, and irregular very low filling and emptying waves in subgroup 1B. The ejection fraction of the left atrial appendage in subgroup $1 \mathrm{~A}$ was significantly better than that in subgroup $1 B$ (mean (SD) $40 \cdot 6(12 \cdot 0) \% v 7 \cdot 6(5 \cdot 0) \%, P<$ $0.0001)$. The spontaneous echo contrast was observed in $90 \%$ of subgroup $1 \mathrm{~B}$ patients but in only $19 \%$ in subgroup $1 \mathrm{~A}$ $(P<0.05)$ and was not found in groups 2 and $3(P<0 \cdot 0001)$. There was a trend for increased prevalence of spontaeous echo contrast in subgroup $1 \mathrm{~A} v$ group $2(P=$ $0.053)$. Thrombi were detected in two cases, and cardiogenic embolism occurred in one case in subgroup 1B. All patients with spontaneous echo contrast had ventricular pacing. Multivariate analysis showed that atrial fibrillation was associated with occurrence of spontaneous echo contrast in patients with ventricular pacing $(P=0.005)$.

Conclusions-The left atrial appendage ejection fraction was lower with ventricular pacing than with synchronous pacing. With ventricular pacing there was a trend towards increased prevalence of left atrial spontaneous echo contrast in patients in sinus rhythm, and a significantly increased prevalence in patients with atrial fibrillation.
(Heart 1997;78:262-267)

Keywords: echocardiography; left atrial appendage; pacemaker; spontaneous echo contrast

It is well known that patients with ventricular pacing have an increased incidence of thromboembolism..$^{1-3}$ In recent years synchronous pacing modes of pacemaker (AAI (R), DDD (R), VDD) have been developed to offer alternative options to VVI (R) mode. It is believed that normal atrioventricular conduction is not only physiologically relevant but also clinically important. In comparison with synchronous pacing, ventricular pacing has the disadvantage of the absence of-or random occurrence of-atrial contraction to ventricular filling; thus atrial fibrillation may be induced. ${ }^{4-6}$ Although the association of atrial fibrillation with thromboembolism is well established, ${ }^{7-9}$ the mechanism of thromboembolism in patients with ventricular pacing is still not clear.

Spontaneous echo contrast of the left atrium and the left atrial appendage can be demonstrated by transoesophageal echocardiography. The appearance of spontaneous atrial echo contrast is believed to be associated with left atrial appendage thrombus, with increased risks of thromboembolism. ${ }^{1011}$ The purpose of our study was (1) to assess the effect of synchronous versus ventricular pacing on the function of the left atrial appendage; and (2) to investigate the correlation between the incidence of left atrial spontaneous echo contrast phenomenon and different pacing modes.

\section{Methods}

PATIENTS

During a six month period, 92 patients with permanent pacemaker underwent transoesophageal echocardiographic exarnination. All patients were in sinus rhythm at the time of the pacemaker implantation. There was no pacemaker syndrome and no patients were taking oral anticoagulants. Patients with concomitant valvar disease were not included. Four patients were excluded because of the presence of persistent spontaneous rhythm at the time of echocardiographic study. Only paced beats were included for analysis at the time of echocardiographic study. The remaining 88 patients, with a mean age of 66.6 (SD 11.3 ) years (range 30 to $88 ; 50$ men, 38 women), were prospectively studied. All

\author{
Taiwan 10002, ROC \\ email: tmlee@ \\ ha.mc.ntu.edu.tw \\ Accepted for publication \\ 8 May 1997
}



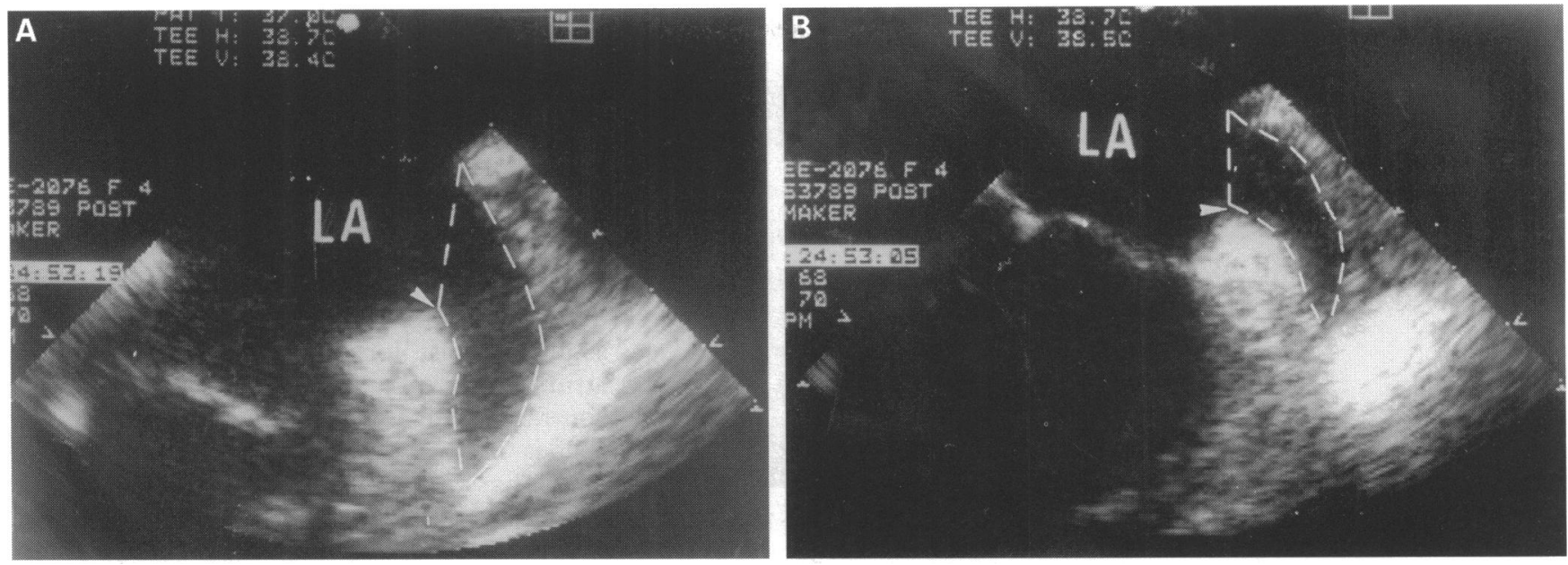

Figure 1 Biplane longitudinal transoesophageal echocardiography in a VVI patient. The maximum $(A)$ and minimum (B) areas of appendage were measured by tracing a line starting from the top of the limbus of the left upper pulmonary vein along the entire endocardial border to the exteriormost portion (arrowhead) of the mitral annulus. LA, left atrium.

patients underwent detailed electrophysiological study before pacemaker implantation. Indications for pacemaker implantation included sick sinus syndrome $(n=67)$ and complete atrioventricular block $(n=21)$. A VVI(R) pacemaker was implanted in 63 patients (ventricular group, group 1). The synchronous group (group 2) consisted of 25 patients with pacemaker types AAI $(R)(n=$ 13), VDD ( $n=2)$, and $\operatorname{DDD}(\mathrm{R})(\mathrm{n}=10)$. Patients in group 1 were further divided into two subgroups on the basis of cardiac rhythm at the time of the transoesophageal echocardiographic study: subgroup $1 \mathrm{~A}$, in sinus rhythm, $\mathrm{n}=42$; subgroup $1 \mathrm{~B}$, in atrial fibrillation, $\mathrm{n}=21$. The clinical characteristics of the patients are given in table 1. For comparison, an additional group was enrolled in the study: this control group (group 3) consisted of 25 normal subjects in sinus rhythm and no apparent heart disease.

\section{ECHOCARDIOGRAPHY}

All patients were examined by transthoracic and transoesophageal echocardiography on the same day. $M$ mode echocardiography was performed in all patients and left atrial size was determined. Transoesophageal echocardiographic examination was performed using a 5 $\mathrm{MHz}$ biplane ( $\mathrm{n}=87$; 35 subgroup $1 \mathrm{~A}, 17$ subgroup 1B, 16 group 2, 19 group 3 ) or multiplane transducer $(n=26)$. Patients had fasted for six hours before transoesophageal echocardiography. Local pharyngeal anaesthesia with $8 \%$ lignocaine spray was the only premedication. During echocardiography, a one lead electrocardiogram was recorded. Informed consent was obtained from all patients and normal control subjects. The study was approved by the institutional research ethics committee.

Left atrial appendage area and flow

Images of the left atrial appendage were obtained in the transverse and longitudinal planes and recorded on Super VHS videotapes for off-line analysis. The boundary of the base of the appendage was defined by a line drawn from the limbus of the left upper pulmonary vein to the exteriormost portion of the mitral annulus. Maximum and minimum left atrial appendage areas were determined by computed planimetry along the endocardial border of the appendage (average of three consecutive values) (fig 1). The ejection fraction of the left atrial appendage was calculated as (maximum area - minimum area)/maximum area. Left atrial appendage velocity profiles were obtained by pulsed wave Doppler interrogation at the orifice of the appendage. The maximum forward positive flow velocity of Doppler left atrial appendage represented the peak emptying velocity (fig $2, a$ wave) and the maximum backward negative flow velocity repre-
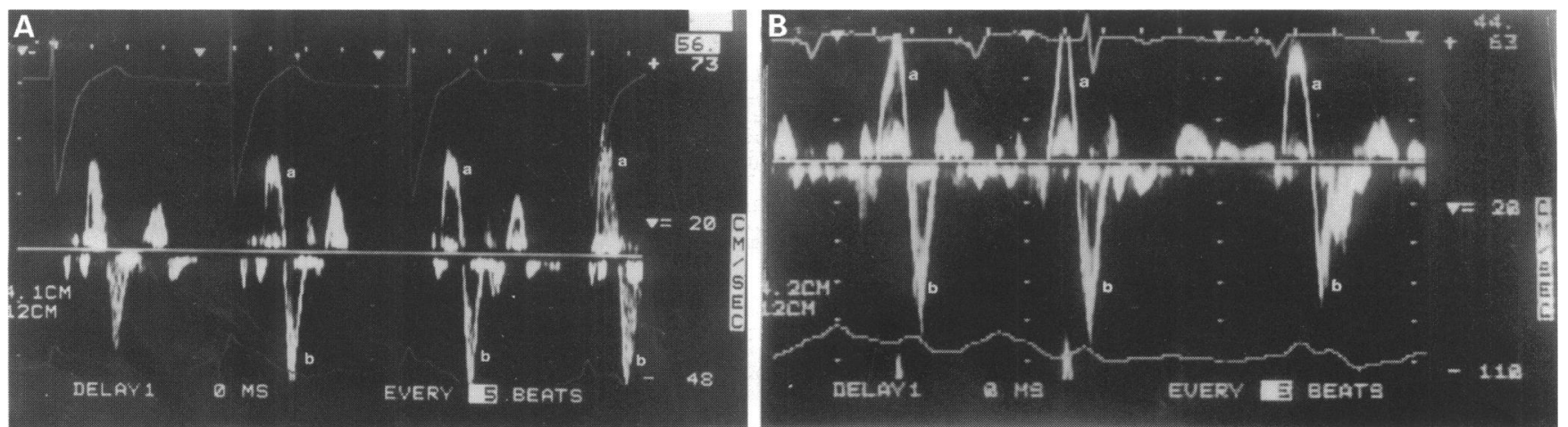

Figure 2 Velocity profiles in VVI patients with preserved sinus activities (subgroup $1 A$ ), (A) with ventriculoatrial conduction and (B) without ventriculoatrial conduction. Both had an underlying disease of sick sinus syndrome. Both show left atrial appendage flow patterns. Regular and well defined emptying (a) waves regularly follow atrial electric activity (seen in $A$, but not seen in B). Filling (b) velocity waves follow the emptying wave. $A$ respiratory trace is shown at the bottom. 


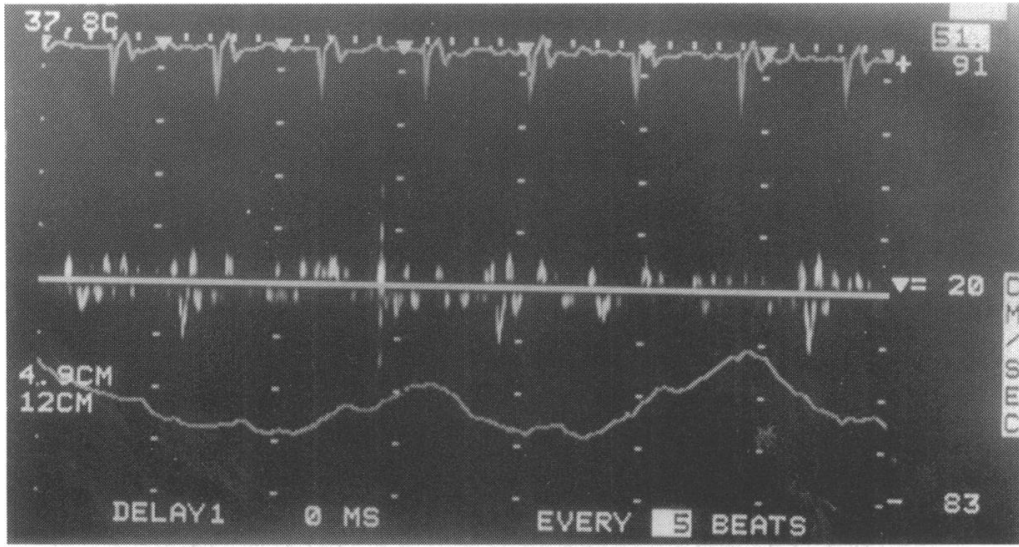

Figure 3 Velocity profiles in a VVI patient with atrial fibrillation (subgroup 1B), an underlying disease of sick sinus syndrome. Left atrial appendage flow patterns show irregular low emptying and filling waves. A respiratory trace is shown at the bottom.

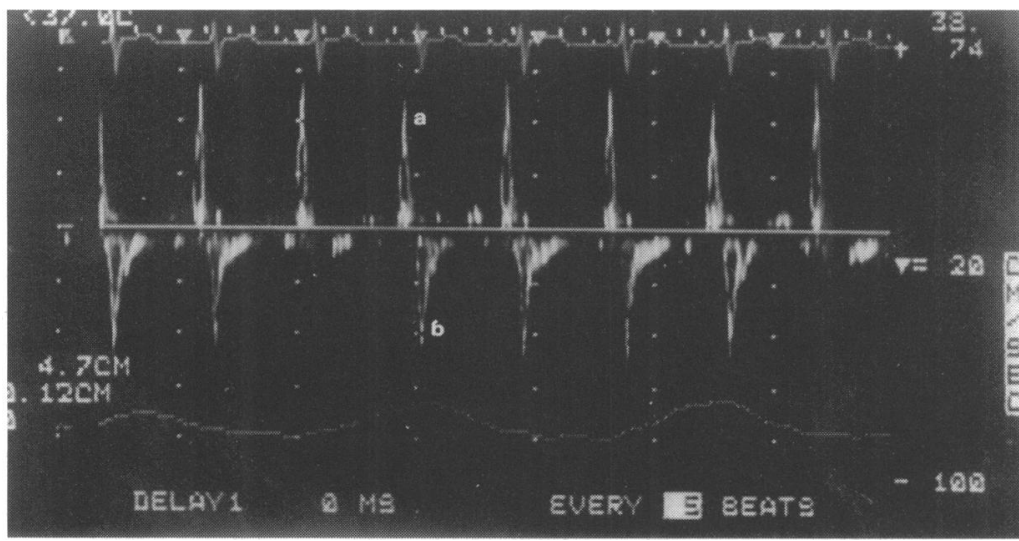

Figure 4 Velocity profiles in a patient with DDD pacemaker (group 2), an underlying disease of complete atrioventricular block. Left atrial appendage flow patterns show well defined emptying (a wave) after electrocardiographically antegrade $P$ wave and filling ( $b$ wave) velocities following the a wave. A respiratory trace is shown at the bottom.

sented the peak filling velocity (fig $2, b$ wave). There were 25 patients in subgroup $1 \mathrm{~A}$ with quadriphasic flows ( $c$ and $d$ waves). Because of their smaller flow velocities, $c$ and $d$ waves did not affect the measurement of peak filling and emptying flow velocities. The ejection fraction of the left atrial appendage and the peak emptying and filling velocities were averaged with each $R R$ interval over a minimum of five cardiac cycles for patients with atrial fibrillation, and over three cardiac cycles for those in sinus rhythm. Interobserver differences were resolved by consensus.
Spontaneous echo contrast and thrombus

Left atrial spontaneous echo contrast was diagnosed by the presence of dynamic smokelike echoes within the atrial cavity, with a characteristic swirling motion distinct from white noise artefact. ${ }^{12}$ The gain was continuously adjusted to ensure the best possible visualisation and to avoid noise artefact. Spontaneous echo contrast was graded as previously described $^{13}$ : grade $0=$ no contrast; grade $1=$ slight contrast localised in parts of the left atrium with a low density; grade 2 = heavy contrast with intense, swirling, smoke-like echoes in the whole atrium. Thrombi were defined as masses adherent to the wall of the left atrial appendage with different echogenic density. Particular attention was paid to differentiating these from pectinate muscles. The presence or absence of spontaneous echo contrast and thrombi was defined by the consensus of two experienced echocardiographers.

\section{STATISTICS}

Values are reported as mean (SD). A $\chi^{2}$ test was used to compare categorical variables. The continuous variables between groups were compared with Student's $t$ test for two tailed unpaired observation. For comparison of multiple groups, analysis of variance was applied. For the identification of independent predictors of spontaneous echo contrast a multivanate regression analysis was used. Two tailed Fisher's exact test was used for patient numbers less than five. A $P$ value $<0.05$ was considered statistically significant.

\section{Results}

Figures 2, 3, and 4 show typical findings of left atrial appendage flow in subgroups $1 \mathrm{~A}$ and $1 \mathrm{~B}$ and group 2.

\section{BASELINE VARIABLES}

The selection of pacing mode was not randomised but was dependent on patients' age, physical activity, prognosis, and cost. The echo studies were performed at a mean time from implantation of 48 (52) months for subgroup 1A, 54 (47) months for subgroup 1B, and 12 (10) months for group 2. The average follow up time in subgroups $1 \mathrm{~A}$ and $1 \mathrm{~B}$ was much longer than in group 2 . The patient age

Table 1 Characteristics of patients and left atrial appendage in different groups

\begin{tabular}{|c|c|c|c|c|}
\hline & \multicolumn{2}{|l|}{ Group 1} & \multirow{2}{*}{$\begin{array}{l}\text { Group 2 } \\
(n=25)\end{array}$} & \multirow{2}{*}{$\begin{array}{l}\text { Control } \\
(n=25)\end{array}$} \\
\hline & $1 A(n=42)$ & $1 B(n=21)$ & & \\
\hline Age (years) & $66.4(10.9)^{\star}$ & $72 \cdot 4(7 \cdot 1) \ddagger$ & $62 \cdot 1(12 \cdot 9)$ & $64 \cdot 6(7 \cdot 9)$ \\
\hline Male/female & $25 / 17$ & $11 / 10$ & $14 / 11$ & $15 / 10$ \\
\hline SSS/CAVB & $32 / 10$ & $19 / 2 \ddagger$ & $16 / 9$ & $-\overline{c o s}$ \\
\hline Set heart rate (beats/min) & $66 \cdot 4(4 \cdot 8) \dagger$ & $66 \cdot 7(4 \cdot 8) \ddagger$ & $72 \cdot 9(5 \cdot 2)$ & $62 \cdot 3(6 \cdot 8) 9$ \\
\hline Follow up period & $48(52) t$ & $54(47) \ddagger$ & $12(10)$ & \\
\hline Left atrial size $(\mathrm{mm})$ & $36.5(3.5)^{\star}$ & $46 \cdot 3(4 \cdot 6) \ddagger$ & $34 \cdot 2(3 \cdot 2)$ & $34 \cdot 8(4 \cdot 2)$ \\
\hline \multirow{8}{*}{$\begin{array}{l}\text { Left atrial appendage parameters } \\
\text { Maximum area }\left(\mathrm{cm}^{2}\right) \\
\text { Minimum area }\left(\mathrm{cm}^{2}\right) \\
\text { Ejection fraction }(\%) \\
\text { Peak filling velocity }(\mathrm{cm} / \mathrm{s}) \\
\text { Peak emptying velocity }(\mathrm{cm} / \mathrm{s}) \\
\text { Spontaneous echo contrast } \\
\text { Thrombus }\end{array}$} & & & & \\
\hline & $5.4(1.4)^{\star}$ & $6 \cdot 1(1 \cdot 4) \ddagger$ & $4 \cdot 7(1 \cdot 3)$ & $4 \cdot 9(2 \cdot 1)$ \\
\hline & $3 \cdot 2(1 \cdot 0)^{\star} \dagger$ & $5 \cdot 6(1 \cdot 2) \ddagger$ & $2 \cdot 6(1 \cdot 2)$ & $2 \cdot 8(1 \cdot 6)$ \\
\hline & $40.6(12.0)^{\star} \dagger$ & $7 \cdot 6(5 \cdot 0) \ddagger$ & $48 \cdot 2(16 \cdot 2)$ & $45 \cdot 7(13.6)$ \\
\hline & $51 \cdot 2(19 \cdot 6)^{\star}$ & $10 \cdot 8(8 \cdot 6) \ddagger$ & $59 \cdot 8(17 \cdot 6)$ & $52.3(16.5)$ \\
\hline & $49 \cdot 3(17 \cdot 8)^{\star}$ & $11 \cdot 4(6.5) \ddagger$ & $51.8(18.3)$ & $53 \cdot 8(23 \cdot 1)$ \\
\hline & $8(19 \%)^{\star}$ & $19(90 \%) \ddagger$ & 0 & 0 \\
\hline & 0 & $2(9 \cdot 5 \%)$ & 0 & 0 \\
\hline
\end{tabular}

Values are number (\%) of patients or mean (SD)

${ }^{\star} \mathrm{P}<0.05 v$ subgroup $1 \mathrm{~B} ;+\mathrm{P}<0.05 v$ group $2 ; \ddagger \mathrm{P}<0.05 v$ group $2 ; \mathbb{P}<0.05 v$ group 2

CAVB, complete atrioventricular block; SSS, sick sinus syndrome. 
in subgroup 1B was significantly higher than in subgroup $1 \mathrm{~A}$ and group 2 , at $72 \cdot 4(7 \cdot 1) v$ $66.4(10.9)$ and $62 \cdot 1(12.9)$ (both $P<0.05)$. The set heart rate of the pacemakers was significantly higher in group 2 than in subgroups $1 \mathrm{~A}$ and $1 \mathrm{~B}$. The size of the left atrium was significantly greater in subgroup $\mathrm{IB}$ than in subgroups $1 \mathrm{~A}$ and groups 2 and 3 , at $46 \cdot 3(4 \cdot 6) v$ $36 \cdot 5(3.5), 34 \cdot 2(3 \cdot 2)$, and $34 \cdot 8(4 \cdot 2) \mathrm{mm}$ (all $\mathrm{P}<0.05)$ (table 1).

\section{LEFT ATRIAL APPENDAGE}

In all patients in subgroup $1 \mathrm{~A}$, the left atrial appendage flow revealed an organised biphasic flow pattern with a peak filling and emptying velocity (fig 2 ). In contrast, all patients from subgroup 1B showed an irregular, very low peak filling and emptying velocity (fig 3). Table 1 compares the left atrial appendage transoesophageal echocardiography parameters in the three groups. The maximum appendage areas were significantly larger in subgroup $1 \mathrm{~B}$ than in subgroup $1 \mathrm{~A}$ and group 2. More striking is the difference in the left atrial appendage ejection fraction, which was significantly reduced in subgroups $1 \mathrm{~A}$ and $1 \mathrm{~B}$. There were almost no visible appendage contractions in subgroup 1B. There were no significant differences of the ejection fraction of the left atrial appendage detected by biplane transoesophageal echocardiography compared with multiplane transoesophageal echocardiography in subgroup $1 \mathrm{~A}(41.2(11.8) v 39.4$ $(12 \cdot 4) \%$, NS) (table 1 ).

Two patterns of left atrial appendage flow were identified in group 1 . In subgroup 1A and groups 2 and 3, Doppler image revealed a biphasic flow pattern with a peak filling and emptying velocity. The $a$ wave occurred after the $\mathrm{P}$ wave and the $b$ wave followed the $a$ wave. In contrast, patients from subgroup 1B showed irregular, very low peak filling veloci-

Table 2 Univariate analysis: clinical and echocardiographic factors related to left atrial spontaneous echo contrast (SEC) in pacemaker patients

\begin{tabular}{|c|c|c|c|}
\hline & $\begin{array}{l}S E C(-) \\
(n=61)\end{array}$ & $\begin{array}{l}S E C(+) \\
(n=27)\end{array}$ & P value \\
\hline Age & $64 \cdot 6(11 \cdot 5)$ & $72 \cdot 1(7 \cdot 7)$ & 0.003 \\
\hline Male/female & $36 / 25$ & $14 / 13$ & NS \\
\hline SSS/CAVB & $43 / 18$ & $24 / 3$ & \\
\hline Ventricular/synchronous & $36 / 25$ & $27 / 0$ & $<0.0001$ \\
\hline Atrial fibrillation & $2(3 \%)$ & $19(70 \%)$ & $<0.0001$ \\
\hline Set heart rate & $69 \cdot 0(6 \cdot 0)$ & $66 \cdot 3(4.9)$ & 0.049 \\
\hline Left atrial appendage & $35 \cdot 4(4 \cdot 2)$ & $44 \cdot 5(3 \cdot 7)$ & $<0.0001$ \\
\hline \multicolumn{4}{|l|}{ Left atrial appendage parameters } \\
\hline Maximum area $\left(\mathrm{cm}^{2}\right)$ & $5 \cdot 2(1 \cdot 5)$ & $5.9(1 \cdot 3)$ & 0.02 \\
\hline Minimum area $\left(\mathrm{cm}^{2}\right)$ & $3 \cdot 0(1 \cdot 2)$ & $5 \cdot 0(1.5)$ & $<0.0001$ \\
\hline Ejection fraction (\%) & $42 \cdot 6(14 \cdot 6)$ & $15 \cdot 5(15 \cdot 3)$ & $<0.0001$ \\
\hline Peak filling velocity $(\mathrm{cm} / \mathrm{s})$ & $53 \cdot 2(19 \cdot 2)$ & $20 \cdot 6(22 \cdot 4)$ & $<0.0001$ \\
\hline Peak emptying velocity $(\mathrm{cm} / \mathrm{s})$ & $48 \cdot 2(18 \cdot 2)$ & $22.9(23.4)$ & $<0.0001$ \\
\hline Thrombus & 0 & $2(7 \%)$ & NS \\
\hline
\end{tabular}

Values are number (\%) of patients or mean (SD).

SSS, sick sinus syndrome; CAVB, complete atrioventricular block.

Table 3 Logistic regression model analysis of risk factors for development of spontaneous echo contrast in patients with ventricular pacing

\begin{tabular}{llll}
\hline Predictors & Odds ratio & $\begin{array}{l}95 \% \text { confidence } \\
\text { interval }\end{array}$ & $P$ value \\
\hline Atrial fibrillation & 21.7 & 2.52 to 187.21 & 0.005 \\
Sick sinus syndrome & 1.8 & 0.47 to 25.42 & 0.447 \\
LA size & 1.6 & 0.55 to 12.73 & 0.364 \\
LAA peak emptying velocity & 0.8 & 0.83 to 1.05 & 0.142 \\
LAA ejection fraction & 15.8 & 0.02 to 9874.31 & 0.372 \\
\hline
\end{tabular}

LA, left atrium; LAA, left atrial appendage. ties (range 3 to $25 \mathrm{~cm} / \mathrm{s}$, mean 10.8 (8.6) $\mathrm{cm} / \mathrm{s}$ ) and peak emptying velocities (3 to 30 $\mathrm{cm} / \mathrm{s}$, mean $11.4(6.5) \mathrm{cm} / \mathrm{s})$. The left atrial appendage peak filling and emptying velocities were significantiy reduced in patients from subgroup 1B compared with patients from subgroups $1 \mathrm{~A}, 2$, and 3 . There were no significant differences in variable echocardiographic parameters between groups 2 and 3 .

\section{SPONTANEOUS ECHO CONTRAST AND} THROMBUS FORMATION

The spontaneous echo contrast phenomenon was not observed in groups 2 and 3; however, it was present in $90 \%$ of subgroup $1 \mathrm{~B}$ patients. The echo contrast was seen in eight patients (19\%) of subgroup $1 \mathrm{~A}$. In subgroup $1 \mathrm{~B}$, left atrial spontaneous echo contrast was graded as slight in 12 patients $(63 \%)$ and heavy in seven $(36 \%)$. In subgroup $1 \mathrm{~A}$, all left atrial spontaneous echo contrast was graded as slight. There was a trend of an increased prevalence of spontaneous echo contrast in subgroup 1A compared with in group 2, although this was not statistically significant $(P=0.053)$. However, the statistic power of the study was 0.45 for $\alpha=0.05$. Two patients from subgroup 1B showed a left atrial appendage thrombus; one experienced ischaemic stroke. The frequency of atrial fibrillation was higher $(P<0.0001)$ in patients with echo contrast than in those without echo contrast (table 2), as were the minimum and maximum atrial appendage areas $(P<0.001$ and $P=0.02$, respectively). The ejection fraction of the atrial appendage was lower in patients with echo contrast than in patients without $(42.6(14.6)$ $v 15.5(15.3) \%, P<0.0001)$. The peak filling and emptying velocities for all patients with echo contrast were lower than for patients without echo contrast (both $\mathrm{P}<0.0001$ ).

Although univariate analysis showed that older age, ventricular pacing, atrial fibrillation, left atrial size, and maximum/minimum areas and peak filling/emptying velocities of the left atrial appendage were significantly related to occurrence of spontaneous echo contrast (table 2), multivariate analysis identified atrial fibrillation as the variable associated with a significantly increased risk of left atrial spontaneous echo contrast in patients with ventricular pacing (table 3 ). The value of -2 $\log \mathrm{L}$ (likelihood ratio test) compared with the full model was $3.00, \mathrm{df}=1(\mathrm{P}=\mathrm{NS})$. All patients with spontaneous echo contrast had ventricular pacing. Ventricular pacing was an independent determinant in the univariate analysis of spontaneous echo contrast.

\section{Discussion}

Our study is the first study to show that patients with ventricular pacing have a high prevalence of impaired left atrial appendage function and the spontaneous echo contrast phenomenon in the left atrium, especially in the subgroup with concomitant atrial fibrillation. For patients with ventricular pacing and sinus rhythm, there is a tendency toward an increased prevalence of spontaneous echo 
contrast, but this was not statistically significant $(P=0.053)$ because of the small number of patients in this subgroup (power $=0.45$ ).

\section{LEFT ATRIAL APPENDAGE}

Left atrial appendage velocities and flow patterns vary according to rhythm. ${ }^{14}$ In sinus rhythm, biphasic or quadriphasic clearly defined emptying and filling flows associated with appendage contraction and relaxation were observed. The $a$ wave, representing forward flow towards the left atrial cavity, was associated with left atrial appendage contraction and began from the initial deflection of the $\mathrm{P}$ wave on the electrocardiogram. The $b$ wave, representing retrograde flow toward the left atrial appendage, was associated with reexpansion of the left atrial appendage and began immediately after the $a$ wave. Some patients with sinus rhythm had quadriphasic flow patterns in the left atrial appendage. The $c$ and $d$ waves are passive flows. The $c$ wave, coinciding in timing with early mitral inflow, was associated with a pressure gradient between the left atrial appendage and the left ventricle on opening of the mitral valve. The $d$ wave, occurring just after the $c$ wave but before appendage contraction, indicated left atrial appendage filling during the diastolic period of mitral inflow. Because the $c$ and $d$ waves were significantly lower in velocity, they did not affect measurement of peak filling and emptying velocities.

In atrial fibrillation, a disorganised flow pattern and reduced velocities of emptying and filling flows are seen. Mugge et al meticulously divided patients with non-rheumatic atrial fibrillation into two subgroups on the basis of left atrial appendage function. One group had a high flow profile with high peak filling and emptying velocities of the left atrial appendage; the other had a low flow profile with very low peak filling and emptying velocities. Their results show that the incidence of spontaneous echo contrast was significantly increased in patients with low left atrial appendage flow than in those with high flow. Porte $e t a l^{15}$ found that left atrial appendage contractile function was a predictor of spontaneous echo contrast. Because the appendage patterns were of the low flow profile type with impaired contractile function in our subgroup $1 \mathrm{~B}$, it was expected that there would be a high incidence of spontaneous echo contrast. Our results are consistent with previous studies ${ }^{81617}$ that patients with low flow profiles of the left atrial appendage have a high incidence of spontaneous echo contrast.

\section{SPONTANEOUS ECHO CONTRAST AND}

THROMBUS FORMATION

The left atrial spontaneous echo contrast phenomenon was significantly more frequent in the ventricular group with atrial fibrillation. One study showed that patients with left atrial spontaneous echo contrast are 27 times more likely to have had a previous stroke or peripheral embolism than those without echo contrast. ${ }^{18}$ Daniel et $a l^{9}$ found that in patients with mitral valve disease, left atrial echo contrast was an independent predictor of left atrial thrombus and cardiogenic embolism. However, only one patient developed cerebral embolism in our study, although there was a higher prevalence of spontaneous echo contrast in the ventricular group. Because only surviving patients were examined and the loss of some patients with severe stroke cannot be ruled out, the real incidence of thromboembolism is probably higher than shown by our study.

MULTIVARIATE PREDICTORS OF SPONTANEOUS ECHO CONTRAST

In this study population, atrial fibrillation was significantly associated with left atrial spontaneous echo contrast in patients with ventricular pacing. The left atrial size, underlying sick sinus syndrome, and left atrial appendage parameters were not predictors of spontaneous echo contrast in patients with ventricular pacing. These results agree with previous observations $^{7}{ }^{11}$, that atrial fibrillation is associated with an increased risk of developing spontaneous echo contrast. However, the relation between ventricular pacing and spontaneous echo contrast has not previously been reported. Our results showed that there was a prevalence of spontaneous echo contrast in patients with ventricular pacing: $19 \%$ in patients with preserved atrial activity and $90 \%$ in patients with atrial fibrillation. One explanation for the high prevalence of spontaneous echo contrast is that ventricular pacing results in a dilated left atrium ${ }^{19}$ and relatively reduced cardiac output. ${ }^{20}$ Conditions favouring stasis of left atrial blood, including left atrial enlargement and low cardiac output, were associated with left atrial spontaneous echo contrast. Therefore ventricular pacing, even with sinus rhythm, was associated with a trend towards the occurrence of spontaneous echo contrast.

\section{CLINICAL IMPLICATIONS}

The effect of ventricular pacing and atrial fibrillation on left atrial appendage function and left atrial spontaneous echo contrast suggests a hidden benefit of synchronous pacing. Left atrial spontaneous echo contrast is a phenomenon that usually appears in regions of blood stasis including an enlarged left atrium, as in this study; however, the mechanism of this phenomenon remains unclear. The pathogenesis of spontaneous echo contrast is complex and includes not only the velocity or shear rate of local blood flow but also factors such as abnormalities of blood components. Siegel et $a l^{21}$ suggested that rouleaux formation of erythrocytes and increased level of serum fibrinogen may be responsible. However, Erbel et al ${ }^{22}$ found increased platelet aggregation in all their patients. Mahony et $a l^{23}$ reported a patient with left ventricular spontaneous echo contrast despite heparin treatment, in whom platelet aggregates were detected in the peripheral blood. Complete spontaneous echo contrast resolution was noted after five days of antiplatelet treatment. Sasaki et $a l^{24}$ significantly reduced the incidence of stroke by using anticoagulants in patients with ventricular 
pacing. Thus further studies are warranted comparing the therapeutic value of anticoagulant and antiplatelet drugs in paced patients with spontaneous echo contrast.

\section{STUDY LIMITATIONS}

This study has limitations. First, it was not randomised. The selection of pacemaker modes depended on patient age, the preference of primary cardiologists, and the cost. Second, the number of patients with ventricular pacing and sinus rhythm was small, which precluded any definite conclusion about the relation between ventricular pacing and spontaneous echo contrast. Third, estimation of the ejection fraction of the left atrial appendage can be influenced by movement of the transoesophageal probe, which will affect the echo plane in which the atrial appendage is evaluated and may cause overestimation or underestimation of the appendage ejection fraction. However, this did not seem to be a problem because this variable was averaged over a minimum of five cardiac cycles in patients with atrial fibrillation and over three cardiac cycles in those in sinus rhythm. Fourth, the rarity of thromboembolic events in this series of patients precluded a definite correlation between systemic embolism and the proposed mechanism involved in thromboembolism in patients with ventricular pacing. Fifth, the presence or absence of spontaneous echo contrast is subjective. However, interpretations were by two experienced cardiologists and any differences were resolved by consensus, so we feel there was little likelihood of misinterpretation. Finally, although some basic clinical variables were not considered in the multivariate analysis, this will not affect the conclusions because all variables with a $\mathrm{P}$ value $<0.05$ in univariate analysis were considered. Values of $\chi^{2}$ for covariates compared with the full model were used to check the differences of $-2 \log \mathrm{L}$ of various models and to select the optimum model for interpretation.

\section{CONCLUSIONS}

Patients with ventricular pacing had a decreased ejection fraction of the left atrial appendage compared with patients with synchronous pacing. With ventricular pacing, there was a trend towards increased prevalence of left atrial spontaneous echo contrast in patients in sinus rhythm, and a significantly high prevalence in patients with atrial fibrillation.

We thank Yuh-Chen Huang for statistical assistance and advice.

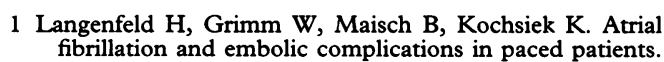
PACE 1988;11:1667-72.

2 Bathen J, Sparr S, Rosketh E. Embolism in sinoatrial dis- ease. Acta Med Scand 1978;203:7-11.

3 Santini M, Alexidou G, Ansalone G, Cacciatore G, Cini R, Turitto G. Relation of prognosis in sick sinus syndrome to age, conduction defects and modes of permanent cardiac pacing. Am 7 Cardiol 1990;65:729-35.

4 Sutton R, Kenny R-A. The natural history of sick sinus syndrome. PACE 1986;9:1110-13.

5 Reimold SC, Lamas GA, Cantillon CO, Antman EM. Risk factors for development of recurrent atrial fibrillation: factors for development of recurrent atrial fibrillation:
role of pacing and clinical variables. Am Heart $\mathcal{F} 1995$; role of pacing
129:1127-32.

6 Santiago D, Warshofsky M, Mandri GL, Di Tullio M, Santiago D, Warshofsky $M$, Mandri GL, Di Tullio M,
Coromilas J, Reiffel J, et al. Left atrial appendage function and thrombus formation in atrial fibrillation-flutter: a transesophageal echocardiographic study. $F \mathrm{Am}$ Coll Cardiol 1994;24:159-64.

7 Mugge A, Kuhn H, Nikutta P, Grote J, Lopez AG, Daniel WG. Assessment of left atrial appendage function by biplane transoesophageal echocardiography in patients with nonrheumatic atrial fibrillation: identification of a subgroup of patients at increased embolic risk. $\mathcal{F} \mathrm{Am}$ Coll Cardiol 1994;23:599-607.

8 Verhorst PMJ, Kamp O, Visser CA, Verheugt FWA. Left atrial appendage flow velocity assessment using transesophageal echocardiography in nonrheumatic atrial fibrillation and systemic embolism. Am $\mathcal{F}$ Cardiol 1993; 71:192-6.

9 Daniel WG, Nellessen U, Schroder E, Nonnast-Daniel B, Bednarski P, Nikutta P, et al. Left atrial spontaneous contrast in mitral valve disease: an indicator for an contrast in mitral valve disease: an indicator for an increased throm $1204-11$.

10 Black IW, Hopkins AP, Lee LCL, Walsh WF, Jacobson BM. Left atrial spontaneous echo contrast: a clinical and BM. Left atrial spontaneous echo contrast: a clinical and
echocardiographic analysis. $\mathcal{F}$ Am Coll Cardiol 1991;18: echocardiog

11 De Belder MA, Lovat LB, Tourikis L, Leech G, Camm A. Left atrial spontaneous contrast echoes: markers of thromboembolic risk in patients with atrial fibrillation. Eur Heart F 1993;14:326-35.

12 Castello R, Pearson AC, Labovitz AJ. Prevalence and clinical implications of atrial spontaneous contrast in patients undergoing transesophageal echocardiography. $A m \mathcal{F}$ Cardiol 1990;65:1149-53.

13 Cormier B, Vahanian A, Iung B, Porte JM, Dadez E, Lazarus A, et al. Influence of percutaneous mitral commissurotomy on left atrial spontaneous contrast of mitral stenosis. Am ₹ Cardiol 1993;71:842-7.

14 Jue J, Winslow T, Fazio G, Redberg RF, Foster E, Schiller NB. Pulsed Doppler characterization of left atrial appendage flow. $\mathcal{F}$ Am Soc Echocardiogr 1993;6:237-44.

15 Porte JM, Cormier B, Iung B, Dadez E, Starkman C, Porte JM, Cormier B, Iung B, Dadez E, Starkman C,
Nallet O, et al. Early assessment by transesophageal Nallet $\mathrm{O}$, et al. Early assessment by transesophageal
echocardiography of left atrial appendage function after echocardiography of left atrial appendage function after
percutaneous mitral commissurotomy. $\mathrm{Am} \mathcal{F}$ Cardiol percutaneous

16 Asanuma T, Tanabe $K$, Yoshitomi H, Shimizu H, Murakami Y, Sano Y, et al. Left atrial appendage in patients with single-chamber ventricular pacing. $A m$ f Cardiol 1995;76:840-2.

17 Fatkin D, Kelly RP, Feneley MP. Relations between left atrial blood velocity, spontaneous echocardiographic contrast and thromboembolic risk in vivo. $\mathcal{F} \mathrm{Am}$ Coll Cardiol 1994;23:961-9.

18 Chimowitz MI, DeGeorgia MA, Poole RM, Hepner A, Armstrong WM. Left atrial spontaneous echo contrast is highly associated with previous stroke in patients with atrial fibrillation or mitral stenosis. Stroke 1993;24: 1015-9.

19 Kubica J, Stolarczyk L, Krzyminska E, Krasowski R, Raczak G, Lubinski A, et al. Left atrial size and wall motion in patients with permanent ventricular and atrial pacing. PACE 1990;13:1737-41.

20 Leclercq C, Gras D, Helloco AL, Nicol L, Mabo P, Daubert C. Hemodynamic importance of preserving the normal sequence of ventricular activation in permanent normal sequence of ventricular activation in p
cardiac pacing. Am Heart $₹$ 1995;129:1133-41.

21 Sigel B, Coelho JC, Spigos DG, Flanigan DP, Schuler JJ, Kasprisin DO, et al. Ultrasonography of blood during stasis and coagulation. Invest Radiol 1981;16:71-6.

22 Erbel R, Stern H, Ehrenthal W, Schreiner G, Treese N, Kramer G, et al. Detection of spontaneous echocardiographic contrast within the left atrium by transesophageal cardiography: spontaneous echocardiographic contrast. Clin Cardiol 1986;9:245-52.

23 Mahony C, Sublett KL, Harrison MR. Resolution of spontaneous contrast with platelet disaggregatory therapy (tri-

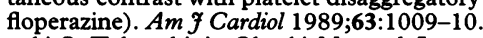

24 Sasaki S, Takeuchi A, Ohzeki M, et al. Long-term followup of paced patients with sick sinus syndrome. In: Steinbach $\mathrm{K}$ et al, eds. Cardiac Pacing. Proceeedings of the Seventh World Symposium on cardiac Pacing. Darmsadt: Steinklppft Verlag, 1983:85-90. 